\title{
14. Sustaining water reform in Australia
}

\author{
Ken Matthews
}

\begin{abstract}
Australia is the driest inhabited continent in the world, so effective water management is of critical importance. In this chapter, I will analyse the reform process of Australian water management. I will first explore the role of the National Water Commission (NWC) - a somewhat misunderstood body - in the process. I will next discuss the specific needs for reform in this field as identified by the commission, and address how best to approach, build and sustain watermanagement reform. I will finally present the National Water Commission's recommendations to the Council of Australian Governments (COAG) on water reform, and our appraisal of the reform process to date.
\end{abstract}

\section{The National Water Commission: a watchdog for water reform}

In 2006 the Commonwealth, states and territories signed the National Water Initiative (NWI), an intergovernmental agreement first tabled in 2004, which called for a change in the way water is managed in Australia. The NWI consisted of 40 pages detailing the specific needs and ways this should be done. As water management is essentially a state responsibility, the NWC was created to monitor the progress of water reform as pledged by each tier of Australian government in the NWI. The commission is perhaps unique for an Australian public administration body as it was established primarily to criticise and with a clear remit to advocate publicly for change. We are also a program manager in a conventional sense, much like a ministry. We provide policy advice, we audit and assess, and we play on the field by being actively involved in improving water management. The NWC's tagline is 'driving national water reform'. I am not aware of a parallel organisation in public administration terms. The commission can initiate its own actions and even do some spending without reference to others - a power related to our critical advocacy role. We are not constrained to avoid policy judgments as some of the family of assessment and audit agencies are, so we can and do make specific recommendations about what needs to be done and specific criticisms about what should not have been done. 
The commission is headed by seven commissioners, each independent and appointed for their expertise. Despite the fact three of the commissioners are nominated jointly by the states and four (including the chair) are nominated by the Commonwealth, we are all required under the commission's governing legislation to act in the best interest of the organisation. Indeed, my observation is that from the first occasion the commissioners met, we quickly forgot who nominated whom. The NWC has thus been an effective exercise in federal cooperation, and, unlike most national organisations, we have a remit to report to COAG regularly and when we see a need.

Every two years the commission conducts a major national assessment of the progress of water reform (see below). We also produce transparency products aimed at casting light on poorly understood areas of water management; examples include a definitive report on Australian water markets and a detailed assessment of the performance of every water utility in Australia, both urban and rural. For the latter project, we compare the performance of each utility against scores of different performance parameters. Both projects help cast light on areas of water management that would otherwise remain opaque.

Another role of the NWC is to produce position statements to help advocate change and propose practical solutions to actually achieve such change. In other words, where we can identify a problem in Australia concerning water management, we will try to articulate the problem and produce something to fix it. The public administration processes to achieve this involve first the $\mathrm{NWC}$, in our capacity as assessor and auditor, diagnosing problems needing to be addressed. If governments accept this advice, the relevant ministers and departmental advisors are then responsible for any responses to our diagnosis. We may also suggest some of that prescription ourselves, but ultimately, this is the role of ministers and government departments.

Policy is next implemented, after which we return to the role of assessing it. Often the diagnosis of a problem is the most difficult part of the process; it can take time to gain popular acceptance, meaning the commission, having established its position on a particular reform, might need to 'incubate' the issue for some time. An example of this occurred early in the commission's existence when we diagnosed that the system of water data in Australia was inadequate for quality policy formulation. We were required to argue this point for a significant period before $\$ 450$ million was finally allocated to the Bureau of Meteorology (BOM) in 2008 to rectify this problem. As a consequence, BOM is no longer simply the foremost source for Australian meteorological data; it is quickly becoming the go-to place for Australian hydrological data. 


\section{Areas for reform in Australian water management}

Let us focus on five major deficiencies identified in our water-management system as examples of the diagnosis process we undertake. First, we have no 'water science' strategy. We found there is no system dedicated to the critical decisions that need to be made about water science. Over the past few years the commission has consistently recommended to COAG the need for a national water-science strategy. In our opinion-developed after consultations with some of Australia's leading water scientists and science users - the lack of such a system hampers priority-setting processes. The existing ways choices are made about where we focus our water science are obscure and, as a consequence, budget-setting processes are non-existent.

Another ramification of having no water-science strategy is that the links between science and policy are currently weak, diminishing the rightful influence scientists should exercise on policy formulation. This has led to some policy makers discounting the value of scientific input in the policyformulation process. Instead, the NWC would like to see a system in which the water managers and the water policy makers are profoundly embedded with the relevant scientists. For the moment though, in Australia, these linkages are weak, and consequently, there are many unmet research needs. What, for example, is the ecological response when you flush a particular wetland with scarce environmental water?

The second deficiency to highlight is the undefined role of environmental water managers in this country. Australia's environmental managers have traditionally been slightly technical, second-tier, public-sector people with no specific sense of self-identity. Further, they have operated under very confused governance. For example, a state government official might be taking decisions about allocation or how best to use such environmental water (that means water for environmental services), and on the same day they might be advising the minister about the allocation and use of consumptive water. In this way, their accountabilities are confounded, conflated and confused.

Third, there is a considerable lack of agreement in environmental water management about which environmental assets are to be protected and the standard to which they should be protected. For instance, not only do we typically not know which are the most important environmental assets to be protected, we also do not know how big or how green a wetland should be, how resilient the ecological system should be, or how often waterings should accommodate a nesting or hatching event. These threshold decisions, when left unmade, give the environmental water manager little chance of success. 
Fourth, environmental water managers lack the necessary scientific input to know what the ecological responses might be if, for example, there is a flush of a wetland. There are different ecological responses that can be observed and we need good science to know whether the water is being used effectivelylet alone efficiently. Additionally, at a strategic level there are still issues to be resolved concerning triple bottom-line objectives: is the environmental water manager responsible only for environmental outcomes, or are there social and economic imperatives to be delivered as well?

Finally, there is a stark lack of cross-jurisdictional integration in the field of Australian water management to the point that the Commonwealth and the states have made very little progress in better aligning their efforts.

Before the NWC cast light on these five deficiencies (among many other examples), they were entrenched as the status quo of Australian water management. Although far from being successfully addressed, the fact these problems have been diagnosed is a positive start. We must now strive for broader acceptance of the need for reform in these areas, which in turn will lead to the process of change. For now, however, we are at the initial stage of diagnosis.

\section{Federalism and water management}

One of the biggest political issues in the area of water management is the division of responsibilities among governments. Water management is essentially a state responsibility, but there exist strong public and media perceptions that due to continual mismanagement by this level of government, a Commonwealth takeover is necessary. This view is not necessarily shared by the NWC, but there is no doubt it is widespread. The problem with such a takeover is that it would not be achieved as easily as some media commentators might suggest. This is not only because the necessary changes to the current constitutional arrangements would lead to legal problems; practically, too, the Commonwealth could not take over, because the states hold all the levers. And, most pertinently, the Commonwealth lacks the necessary expertise.

Complicated by such problems, responsibility has instead regressed to management by intergovernmental agreements and intergovernmental machinery. This in turn precipitates the following implications: negotiated outcomes, lowest common denominator outcomes, management by committee, slow agreements, reduced scope for Commonwealth policy leadership and national outcomes that generally become compromised. Because the states have the resources, the capacity and the constitutional responsibility, delivery of water management will have to continue via this tier of government. Yet with intergovernmental machinery complicating this process, it appears likely the cycle of public and media dissatisfaction with the current division of responsibility will continue. 


\section{Approaching water reform}

Once water management deficiencies have been diagnosed and accepted, how then should subsequent reforms be approached to ensure they become embedded? First, at the NWC, we believe it is fundamental to think strategically during the diagnosis process about what needs to be reformed, so the necessary research can be commissioned and we can position ourselves at the fall of the ball'. One of the biggest challenges for the reformer is compiling the necessary evidence and data to support their case once the public debate so demands it. In the instance of Australian water reform, this can be done with the contribution of such organisations as the Productivity Commission, the Australian Bureau of Agricultural and Resource Economics (ABARE), or the NWC itself. What we at the commission espouse is, however, not a research-led reform agenda, but a research-equipped reform agenda. To achieve this, we need to commission research that becomes available at exactly the right time. As any water scientist will say, there is nothing more frustrating than working in an area for years, finally getting the call from the policy maker requesting advice in that area within a fortnight, only to have to tell them that it takes two years to produce the necessary scientific advice. Timing is therefore critical to approach water management reform.

Second, a national framework that allows for local solutions is necessary to approach water reform. The previously mentioned National Water Initiative fits this description. The NWI is strategic in terms of the overall shared national outcomes to which all levels of government have committed, but at the same time it provides flexibility for jurisdictions to legislate in their own way to reflect their own unique conditions. This of course leads to the age-old argument that Commonwealth and state people have about uniformity versus consistency, which is simplistic and unhelpful. Rather, in the majority of water management reform cases, some provision for local solutions is critical to success.

It is also important to distinguish between a national reform agenda and a Commonwealth reform agenda. A national initiative - free from the resentment often attached to a Commonwealth equivalent-can improve buy-in and ownership. As the term implies, it should have a truly national character, defined by trans-jurisdictional cooperation, as we find with the NWI. Indeed, the NWI attempts to combine strategic policy - that is, directions - with some practical ways to achieve them. Time lines are used to establish the broad objectives for future water management each signatory shares, with a specific set of commitments to be met by each party by specified deadlines. Despite the fact that, because of some slippage, many of these commitments are yet to be met, the NWC believes the driving effect of having these time lines, coupled with annual or two-yearly assessments made by us, seems to work. 
Additionally, for national water-reform initiatives to succeed there needs to be enough in the package for all parties, delivered at a balanced rate. The NWI is unusual in that it has had to carry not just the Commonwealth and state governments, but also the wide range of interest groups involved in water. Despite the fact these range from the reactionary (for example, some irrigators) to the idealistic (for example, some environmentalists), no interest group (or government) has yet walked away from the NWI. Now four years since it was tabled, the initiative could easily have failed, yet it continues to be an agreement that sticks, partly because there is enough in the package for everyone. For example, both irrigators and environmentalists find enormous value in getting property rights to water because one of the principles of the NWI is that there should be statutory equality for environmental and consumptive water. Such an arrangement is quite a far-reaching strategic change in the way water is managed in Australia. There are many other such examples of shared interests in the NWI, but this one alone has kept stakeholders committed to the package.

Providing clear and effective information to affected communities is also critical to approaching water reform, when communities in the Murray-Darling Basin are completely unaware of what their future holds for them. Indeed, the NWC has argued that there are better ways to produce the Murray-Darling Basin Plan. Had better community consultation occurred-such as, for example, progressive and interim exposure of ideas and objectives-people could have had a clearer idea of reform directions. Under the current process for developing the plan, the basin's communities, irrigators, stakeholders and environmental groups have little or no idea of what is in store for them and a negative reaction is almost certain. Surely this is not the best way to proceed. Clarity about burdensharing arrangements - or what is called 'risk assignment' in the NWI-is especially crucial. Both this and the accompanying sense of fairness must be made transparent to people who are involved.

In thinking of stakeholder consultation, we should seek to address what issues are at 'stake', or what could be obtained for the stakeholder from the reform process. Trying to align a set of interests rather than just mindlessly dealing with a stakeholder is a much more productive and honest way of approaching consultation. I encourage my stakeholder management teams to be focused and sharp about how and why they are engaging with stakeholders.

Consultation needs to be genuine and serious at both the peak body and the grassroots level. For the former, we have a stakeholder reference group at the NWC that meets several times a year. The aim is to gather all the relevant players and their differing perspectives: the National Farmers Federation, the Business Council, the Australian Conservation Foundation and so on. At these meetings, we attempt to respectfully listen to each party and then share some of our perspectives as well - a markedly different approach to the common mistake 
made by bureaucrats of simply talking at stakeholders. We are conscious to dedicate a few hours at the beginning of each of these meetings to letting stakeholders talk to each other-an experience they find positive. Through this interaction, the stakeholders leave knowing not only what we are thinking and doing, but what each other is thinking and doing as well. Overwhelmingly positive feedback from various peak-body stakeholders indicates this model of consultation has been successful.

At the grassroots level, an altogether different approach is required. In order to gain respect from local actors, it is wise to travel to meetings alone, regardless of whether the news you have for the stakeholders is good or bad. There is no doubt it is not easy to deliver bad news to a group of angry irrigators. But by engaging in the discussion as personally as you can, the best possible outcome is usually achieved. This local approach is an important complement to the more formal style of peak-body consultation.

Finally, water-policy reform should be approached through a wider environmental context; it should be nested in natural-resource management, rather than being seen as a discrete, disconnected natural resource.

\section{Building support for water reform}

To build sophisticated support for water management reform, we at the commission have found the COAG imprimatur invaluable. The NWI is not just another agreement; it is a COAG-level water agreement that carries the signature of premiers, chief ministers and the Prime Minister. Consequently, it can be a persuasive tool for both governments and stakeholders. With such highprofile signatories comes a certain degree of momentum that we are using to our advantage.

To date, we have enlisted national advocates for the NWI and for wider water reform in general, including the Committee for Economic Development of Australia (CEDA), the Business Council of Australia, and peak-level irrigation and environmental groups. All are non-governmental actors; all are championing the cause of water reform. Additionally, the NWC is attempting to align the commentaries on water management of various respected national agencies, including the Australian National Audit Office (ANAO), the Productivity Commission, the Australian Competition and Consumer Commission (ACCC) and others. In this we have had some modest success; there is a general consensus among these agencies about what should be the future direction of Australian water management. This shared belief, together with third-party endorsements (for example, from CEDA), has helped build a strong wave of public support. 
Second, to maximise the chances of successfully building public support for a reform, government reformers must time their run according to the election cycle. In the life of a government, the worst time to launch a reform campaign is probably just before an election. Conversely, the right time is in the early stages of a government. Canny, reform-minded officials are sensitive to their ministers' aspirations to leave their own legacy and pursue their own big issues during their ministership - including policy reform. Far from being manipulative, hitching your reform star to a minister's interests and aspirations is mutually supportive and entirely pragmatic. It also requires, however, the nous to sense what the minister is searching for and how your reform agenda can be compatible.

Third, policy makers looking to build support for their reform are advantaged by the fact that while Australia is a large country, it is a small nation. By this I mean that compared with the United States or Europe, for example, it is relatively easy to deal personally with decision makers. In each of the different portfolios I have worked in over my career, if there was an issue to be solved, I simply picked up the phone, called my counterpart CEO and said: 'we have a problem, how are we going to deal with this?' Such an approach would not be possible for my counterpart in the United States and certainly not in Europe. Consequently, Australia possesses a more governable and therefore potentially more reformable economy and polity than many countries - an advantage that provides the opportunity to forge a group of like-minded reformists among the Commonwealth and state governments. Depending on where you sit, successful dealings with one's counterparts can lead to a small but powerful group of reform advocates. In this way, Australia's small network of policy professionals can be a powerful institutional force for change - albeit an informal one.

\section{Successfully entrenching water reform}

The most important stage of any reform process is introducing automatic processes to embed and sustain the original reform - something the NWC is currently trying to achieve. The best example is markets, whose introduction will lead to further developments occurring autonomously. When we finally established water markets, there was no going back. Even the conservative irrigators who said 'markets over my dead body' are now actively using those markets and are gracious to admit they were wrong. Further, not only are such developments usually irreversible, but the self-managing nature of the process means government interference is no longer necessary. Australian water markets are now recognised as the most developed and sophisticated of their kind anywhere, such that we frequently receive international visitors coming to study the model instituted here. 
Water markets cannot exist, however, without property rights. This is why under the NWI property rights were secured for irrigators - something that affirmed their commitment to the scheme. Environmentalists, too, championed the attainment of property rights as part of the NWI, because this opened the prospect of securing perpetual allocations of water for the environment. This example shows how by incorporating incentives and disincentives into a reform, relevant parties will act according to their own self-interests - a better outcome than enforcement through regulation.

Markets are one example of a self-sustaining process for change - critical to the successful entrenchment of reform. Another way of achieving such automaticity is to create, or modify, an institution. Once created, institutions will carry forward their responsibilities, particularly if they are of a statutory nature. An institution bound by legal obligations - particularly new or modified laws - can become an effective agent for autonomously entrenching a policy reform. This prevents the need for continually reworking the original reform year after year.

Adaptive-management obligations are another effective way to entrench policy reform. Adaptive management is a common term in water, referring to the idea that if some wetland were to be irrigated with environmental water, a scientific observation of the ecological response would be needed to advise on any modifications needed to the wetting regime. While this adaptivemanagement cycle is a generic concept that could apply to any sector, it is of particular relevance to water management, where it can act as a powerful means of entrenching self-sustaining reform. Adjustment assistance is obviously an important part of this process of changing management practices. This can come in many forms: it might be through buy-outs, or it can be a continuing process of delivering economic resources to stakeholders so as to ensure they continue to get part of the yield from the reforms, thus ensuring their interests continue to align with those of the reform process.

Governments will be required to devote more resources to achieving the goal of sustainable water management reform. Although water is fundamentally a state responsibility in Australia, too often the state water agencies are underresourced and lacking capacity, hampering their ability to effectively manage water. And, despite having trumpeted the benefits of having a small, cohesive circle of reform-oriented professionals able to share expertise, it does not mean they would not benefit from more expertise in the field. Typically, there is only a handful of people in each state who deal with water reform, meaning their capacity to do more or to change direction is limited. There has been a recent reluctance by some governments to allocate resources for more officials in this area, but at the NWC it is our belief that the best way to make sustainable reform happen is to build capacity. 
Regular public reporting is yet another prerequisite to entrenching policy reform. Indeed this is one of the principal reasons the NWC was established; we have a mandate to produce public reports on various aspects of water management, thus ensuring progress on the promises governments make on managing water is stringently monitored. In fact, we are required to publish reports at least every two years - an arrangement that has so far proved quite effective in helping sustain the reform process. In order to cast light on issues that are not otherwise well understood, all our reports are published and we try to make decision making transparent. For example, we have recommended that where a minister needs to take a decision not to deliver environmental water as promised, the reasoning behind that decision needs to be made public so that people can make their own judgments about the wisdom of making such a move.

Nurturing local champions is another strategy to maximise the chances of sustainable reform. In the NWC two of our commissioners are irrigators, and they are extremely effective in talking to their community counterparts through shared experiences and in a language they understand. The problem with the local-champion approach in rural and regional issues is that often capacity is so thin in regional communities there is a real risk of reform fatigue, because the same people have to carry the load the whole time.

Finally, for a reform to endure it must be able to stay fresh and relevant in the face of ever-changing contemporary challenges. While the NWI dates from 2004, it would be foolish for us at the commission to insist on nothing short of strict adherence to its original conditions. Rather than expecting governments to maintain the exact promises their predecessors made six years ago, we have accepted that circumstances have since changed, and consequently allow for a degree of give on particular commitments within the original NWI. Sound judgment is needed by those involved in order to achieve this successful adaptation, and thus maximise a reform's chances of enduring into the future.

\section{The NWC's perspective: some recommendations for COAG}

In order to best manage Australia's water resources into the future, the NWC has prepared several recommendations for COAG to consider, two of which I will discuss. First, we would like to see an annual program of COAG-endorsed reforms for the year ahead that responds to our assessments of how water reform is going and what is emerging. Our last report to COAG, for instance, contained 68 recommendations and more than 100 different findings. These included recommendations about how to evolve the NWI, building on the general concepts that it originally contained. Adjusting reform priorities according to progress makes sense. 
Second, we have recommended COAG creates a complementary, voluntary reform process alongside the National Partnership Payments (NPPs). While we believe the NPPs have largely been successful, they have the significant disadvantage of typically being negotiated between the Commonwealth and the states, creating the real possibility of reform ambitions and aspirations being rounded down. As an alternative to negotiated reforms, the NWC would like to see the Commonwealth Government putting its money on the stump, specifying the exact reform it would like to see. Under this approach, the specific reform would be defined in an ambitious, non-negotiated way, with the states having the choice of taking the money or not. Alongside the current NPPs, such a complementary arrangement could further strengthen the water-reform process.

\section{An assessment of the water-reform process}

Four years after the NWI was first tabled, how is the NWI's reform agenda progressing in the eyes of the NWC? The NWI is unique in Australian policyreform sectors for several reasons. First, the concept of an agreed agenda containing detailed time lines about what needs to be reformed is unprecedented. Further, compared with other sectors, here, there is reasonable stakeholder consensus; no-one has yet walked away from the NWI. There is also an independent national assessor in the form of the NWC, created by governments to criticise governments. This, especially, is a rare mechanism in public administration.

So, what aspects of water reform are we getting right? First, we have a waterreform framework in the guise of the NWI, and, despite tough conditions, that reform process is going better than it would without such a framework. In short, if we did not have an agreed agenda, there would be much that would not be happening. Second, there is currently an unprecedented amount of money devoted to water management in Australia; today we talk in billions of dollars, whereas 10 years ago we were lucky to get millions. Third, Australia has recently emerged as a world leader in opening up water markets - a development that has proved to be invaluable during the recent drought. In fact, our modelling shows Australians would have been much worse off dealing with the drought without water trading.

We have also had success in urban water supply diversification. Every metropolitan city in Australia and many inland cities have now diversified their supply from dams, ensuring a more secure portfolio of different sources of supply. And while such sources of diversification-desalination, recycled water, urban purchases of rural water, and stormwater capture-have differing costs, the fact is that people are prepared to pay for water security as opposed to simply relying on water from the hills, which has previously proven to be insecure. 
Finally, we have achieved some truly historic governance reforms in the MurrayDarling Basin. Obviously, water management is a national issue and much more than the Murray-Darling Basin, but the basin is undeniably a major part of our system. Significant changes to the way the Murray-Darling Basin is managed are currently developing, and for the first time water is now being recovered for the environment, with both major political parties recently committing to a continuation of that process.

And yet, there are many aspects of water reform that are still failing. First, 15 years after the commitment to fix it was first made, the problem of overallocation is still to be addressed. Over-allocation refers to the assignment of rights to water beyond the sustainable capacity of the water system to deliver it. This problem could be combated by creating sophisticated water management plans for each Australian river valley. Despite the promise of this, 40 per cent of such proposed plans have still not been developed, and other plans that commit to providing water security, stability, certainty and predictability have been suspended because of the drought.

Moreover, environmental aims remain unclear and some of the environmental flows that were initially agreed to have been cut. There is still a lack of clarity about environmental aims, which poses both a significant scientific and a reform challenge. What needs to be added is the reduction of some environmental flows. Obviously, such an approach is contrary to the property-rights concept of equal statutory status for the environment and for consumptive uses.

Next, there are still barriers to water trading in this country. For example, irrigation communities are yet to gain the necessary clarity and confidence about the future to effectively address the challenge of climate change. The fact that irrigators - or indeed regional communities - who are heavily reliant on environmental assets cannot plan more than three months ahead because they are not aware of what exactly the reform process entails is a serious problem. In such an ambiguous policy climate, how can these communities, businesses, individuals and families expect to make long-term investments and decisions?

Turning to urban water, another problem is the widespread presence of water restrictions - and the widespread belief they are a positive force. Water restrictions are arbitrary, inequitable, and take the pressure off urban water suppliers to do their job correctly. Unfair and overly costly, water restrictions should be regarded as a last resort to curbing water use. Their rightful role is that of a buffer, and they thus should be removed as soon as water supply improves. If we overuse this tool, we will not have a reserve capacity for when the spike really dives. 
Yet another impediment to successful water reform is the often disappointing performance of the various governments involved. Intergovernmental decisions remain slow, the states continue to be hampered by resource constraints, and there is still much bickering between the Commonwealth and the states and between various states (most notably between South Australia and Victoria and Victoria and New South Wales). Such conflicts are both regrettable and embarrassing for all parties involved. The opinion of the commission is that renewed momentum for reform is needed to address this last problem, and we have therefore recommended a substantial package to COAG to deal with it. That said, the increasing role of the Commonwealth as a significant player in Australian water management is a positive development. Five or six years ago, the Commonwealth was not a significant actor in the field of water management, but that is certainly no longer the case. As a consequence, we are witnessing many institutional adjustments as the Commonwealth moves into this space.

\section{Concluding remarks}

Although the remaining problems illustrate the magnitude of existing waterreform challenges, the NWC firmly believes the current prescriptions of the NWI (for example, property rights and equal status for the environment) are the right ones to achieve such a systemic overhaul. There are some tangible examples of successful reforms due to such prescriptions; water trading is still the most significant, but the pace of reform has slowed. We are convinced of the virtues of the current prescriptions, but we must strive to convince an oftensceptical public (especially in the regions) to stay on board.

As a final observation, my experience with reforms in different portfolios has been that there is no shortage of strategic policy thinkers at the senior executive level. In fact, as I would sit around the board table in large organisations, I would be surrounded by strategic thinkers. And yet, what I would be looking for would be the practical, concrete, 'doing' people who had been weeded out because the smart strategic thinkers were promoted up the line! It is not sufficient to have a table surrounded with only strategic reformers; we need always to assemble a team that includes those tactical, concrete people with an interest in deadlines and getting jobs done. Strategic thinkers are of course vital, but it takes more than strategic thinkers to effectively entrench reform. 